\title{
PARTICIPACIÓN DE LAS MUJERES EN EL PODER POLÍTICO'
}

\author{
Cristina Segura Graíño \\ A.C. Al-Mudayna \\ Universidad Complutense de Madrid
}

Las mujeres han sufrido durante los tiempos, por los menos durante los tiempos históricos que son los que conocemos, las imposiciones del sistema patriarcal. Éste ha organizado la sociedad en dos construcciones culturales, los géneros masculino y femenino, y ha asignado a cada uno de ellos unas funciones de acuerdo con el modelo elaborado social y culturalmente. A cada modelo se han asignado unas funciones diferentes y, también, se han asignado unos espacios donde proyectarse, públicos o domésticos. Lo público es propio de lo masculino, mientras que el género femenino debe actuar y recluirse en el espacio doméstico. Estos espacios son realidades materiales como la casa, pero también ámbitos de pensamiento, en los que precisamente se elabora la mentalidad que domina todo el transcurrir social. A las mujeres lo público les está vedado, ellas no deben intervenir en estos ámbitos, sino recluirse en lo doméstico, en su casa y no pretender lograr la transcendencia que facilita la actuación en un espacio público. Lo político es lo público por excelencia pues es lo que a todos pertenece. Por tanto, es en los espacios públicos donde desarrolla la política y como consecuencia el poder. El poder político pertenece al ámbito público, que es masculino y al que no tienen acceso las mujeres. Por tanto, como

'Dedico este trabajo a la Memoria del Prof. Dr. D. Emilio Sáez, fallecido en 1988.

"Anuario de Estudios Medievales", 25 (1995) 
primera premisa hay que tener en cuenta que el poder político no es de la incumbencia de las mujeres; pertenece a los hombres y ellos deben ser los que se ocupen de él. Esto aparta totalmente del poder político a las mujeres. Ésta es la teoría que hay que aceptar y de la que hay que partir para analizar las relaciones de las mujeres con el poder político, del que en principio están alejadas. Esta es la mentalidad dominante, el marco jurídico referencial al que se puede invocar en cualquier momento: El poder no es propio de mujeres. Según los criterios patriarcales, las mujeres están apartadas de él. A los que pertenece el poder es a los hombres, esto no quiere decir que en un determinado momento encontremos alguna infanta o reina con gran poder efectivo, la "potestas", para disponer de los asuntos políticos. Pero esta situación siempre es la excepción frente a la norma que es la exclusión de las mujeres del poder. La sociedad queda, por tanto, dividida en dos grandes grupos, hombres y mujeres, atendiendo el sexo. Esta división se mantiene si aplicamos el género como categoría de análisis. Pienso que no es necesario aclarar que sexo, que viene dado por naturaleza y solo señala diferencias naturales, no debe confundirse con género que es una construcción cultural que impone a hombres y a mujeres unas diferentes formas de comportamiento y actuación.

Mientras que el patriarcado se extiende a lo largo de la Historia, la sociedad feudal tuvo su máximo apogeo en los siglos que coinciden con el Medievo. El sistema feudal también organizó la sociedad en dos grandes grupos. Los privilegiados y los no privilegiados. Los primeros fueron una minoría que se beneficiaban de las plusvalías que generaban los segundos. Los privilegiados eran los poderosos, los que ostentaban el poder. Poder político, económico y social que luchaban por mantener dentro del grupo. El poder estaba en manos de unos pocos que pretendían poseerlo y transmitirlo a sus descendientes, a sus hijos varones y así perpetuarlo dentro del grupo privilegiado. Por ello había dos grandes preocupaciones, la legitimidad de los hijos y arbitrar un sistema para solucionar los problemas que se planteaban cuando un individuo moría antes de que su hijo pudiera hacerse cargo de la herencia paterna. Problema acuciante en aquel momento en que la mortalidad infantil era grande y en que la violencia de la sociedad, los peligros, la falta de higiene, etc. hacían la esperanza media de vida muy escasa. Para solucionar la primera cuestión se inventó la honra y la reclusión de las mujeres en sus casas con unos controles durísimos para evitar que mantuvieran relaciones con nadie nada más que con otras mujeres 
y con los parientes varones muy próximos; así los hombres podían tener certeza de que los hijos de sus mujeres lo eran también de ellos.

La segunda preocupación requería otro tipo de solución de carácter público, que implicara a todos. Mientras que la honra era problema de cada uno, lo relacionado con la herencia afectaba a todos y debía recibir un tratamiento estable que todos conocieran, que todos aceptaran y que el poder se preocupara de arbitrarlo y de velar por su cumplimiento. La solución adoptada permitía mantener la herencia dentro de la familia y abría una posibilidad de participación de las mujeres. Esta posibilidad derivaba de la necesidad de arbitrar este mecanismo de defensa para que todo se mantuviera dentro del orden conveniente y establecido.

La práctica jurídica feudal establecía que la herencia se transmita por vía masculina. En el caso que en un matrimonio no hubiera ningún hijo varón, entonces era la hija mayor la que heredaba, siempre que contrajera un matrimonio de acuerdo con su padre o con el señor, si era huérfana. Su marido se encargaba de administrar la herencia, que podía ser un reino o un feudo, puesto que se consideraba a las mujeres incapaces para este ejercicio. Las mujeres transmitían el beneficio, reino o feudo, el poder o "autoritas y su ejercicio o "potestas". En este caso las mujeres eran un puente entre su padre y su hijo, la herencia permanecía en la familia a través de ellas, que podían ostentar el poder, ser reconocidas reinas o señoras, pero no podían ejercerlo, es decir, ellas no podían ejercer la administración de su herencia que correspondía a su marido. Las mujeres transmitían unos derechos, la "potestas" que no podían ejercer. En cambio, si el marido moría dejando un hijo menor, era la mujer la que se encargaba de la administración del feudo o del reino hasta que el hijo pudiera desempeñar estas funciones. En este caso se autorizaba a las mujeres a ejercer el poder, esto es la regencia del menor. Hay una paradoja puesto que en el primer caso las mujeres no pueden ejercer el, es decir el gobierno del reino o del feudo, mientras que en el segundo caso precisamente lo que ejercen es la "potestas", la regencia del menor. El sistema elabora y aplica unas pautas de comportamiento no coherentes sino adaptadas a las necesidades de cada momento para evitar que el propio sistema se tambalee con principios y prácticas ajenas al derecho feudal.

Por este motivo, en todos los reinos de la Península, si exceptuamos Cataluña, hubo mujeres que llegaron a poseer la Corona, como después se analizará. Asimismo, las mujeres que heredaron un señorío fueron muy numerosas aunque su importancia fue irrelevante puesto que siempre se 
presentan como meras transmisoras de la herencia para sus hijos. La constatación de la existencia de reinas y de estas señoras que heredaron un señorío, puede llevar al error de considerar que las mujeres ejercieron el poder como los hombres ya que llegaron a ocupar el trono unas, y la mayoría de las mujeres de la nobleza tuvieron algún tipo de relación con su señorío, bien con el que habían heredado al no tener hermanos varones, bien con el que habían recibido de su padre como dote, o bien con el que pertenecía a su marido muerto y que administraron hasta la mayoría de edad de su hijo; pero, en todos los casos fueron meras transmisoras de la herencia para su hijo. No obstante, ante esta realidad se pueden a plantear varias preguntas. ¿Las mujeres ejercieron el poder igual que los hombres? ¿Tuvieron los mismos derechos para acceder a él? En el caso que estas preguntas se pudieran contestar afimativamente habría que concluir que las mujeres, bien como reinas o bien como señoras feudales, habían tenido poder y lo habían ejercido, es decir que tuvieron participación en el poder. Esta situación no puede inducir a error y hay que analizarla minuciosamente. En primer lugar el sistema de herencia es diferente para hombres y mujeres, más aún en lo relativo a la sucesión en el poder. Los varones siempre son primeros a las mujeres y éstas no pueden acceder a la Corona real o feudal aunque sean mayores y su hermano varón menor.

El ejemplo de esta situación fue Berenguela de Castilla que fue olvidada en beneficio de su hermano Enrique a la muerte de Alfonso VIII (1214). Berenguela era una inteligente mujer mientras que Enrique era un niño de corta edad. Ella no heredaba la Corona, que pasaba a su hermano que era reconocido como rey de Castilla. Pero si heredaba "potestas", ya que se encargaba de la regencia del niño Enrique I. Todavía la situación se complicó más con la muerte del rey (1217). Entonces Berenguela, como primogénita de Alfonso VIII heredó la Corona de Castilla de su padre y la "potestas", fue reconocida como reina, título que conservó hasta su muerte (1246), pero dejó de ejercer el poder que depositó en manos de su hijo mayor Fernando III reconocido como rey de Castilla y pronto de León por la muerte de su padre (1230). Berenguela transmitía sus derechos a su hijo Fernando que compartió con su madre la Corona en Castilla, sucediendo a su tío Enrique y a su abuelo Alfonso. Pero la "potestas", que estaba ejerciéndola Berenguela en la minoría de Enrique, pasó a Fernando que rápidamente comenzó a actuar como rey y a administrar el reino. El caso de Berenguela es ejemplar por el estricto cumplimiento de la norma jurídica. También en él hay una gran paradoja, cuando convenía para el 
mantenimiento del orden impuesto Berenguela no tenía derecho a la "potestas", que pasaba a los varones de su familia; pero cuando convenía y se requería su colaboración, se le ofrecía la posibilidad de ejercerla, cosa que hizo a largo de su vida con gran dedicación en ayuda de su hijo. Berenguela es el ejemplo claro de la utilización que se hacía de las mujeres para que el sistema se perpetuara. Según las necesidades de cada momento, se tomaban las decisiones oportunas sin mantener una actuación coherente entre ellas. Como las mujeres no tenían otra salida, aunque algunas fueran conscientes de su situación y la denunciaron, siempre hubieron de acatar lo dispuesto sobre la herencia en lo relacionado con el poder. En este caso las normas se respetaban y jurídicamente las mujeres fueron apartadas del poder y convertidas en meras transmisoras de la herencia.

Antes de encontrar el ejemplo de Berenguela, que es en sí mismo una constatación de la utilización que el poder hacía de las mujeres, hay otra larga serie de mujeres que transmitieron derechos a la Corona o accedieron al trono en el reino de Asturias, en Castilla, Portugal, Navarra o la Corona de Aragón. Es muy difícil precisar cual es el tratamiento que recibieron las mujeres en la temprana monarquía asturleonesa en la que ninguna mujer llegó a ocupar el trono. Dos posibilidades había para el acceso a la Corona. Bien la elección como en el reino visigodo o bien la sucesión como imponía la norma feudal. En el primer caso las mujeres estaban totalmente excluidas pues solo podían ser elegidos los varones; los menores y las mujeres no tenían esta capacidad. Pero es más plausible que el poder se transmitiera de forma hereditaria, atendiendo a la transmisión en el beneficio que ya aparece en los códigos germanos. En este caso si habría que valorar la intervención femenina puesto que en ellos aparecen como transmisoras de derechos.

Los estudiosos de estos siglos altomedievales concluyen, atendiendo a las informaciones que proporciona la Crónica de Alfonso III, que la sucesión estaba vinculada a los descendientes de Pelayo que enlazó por la boda de su hija con la familia del duque Pedro de Cantabria. El sistema hereditario estaba plenamente consolidado en el siglo $\mathrm{X}$. La norma que imperaba era la sucesión del hijo varón mayor. Las mujeres quedaban excluidas de la sucesión aunque podían transmitir sus derechos a sus hijos, si faltaban otros parientes varones. Esta práctica es la norma que se sigue en la transmisión feudal en todo Europa y no aporta ninguna novedad. No obstante, en los primeros pasos de la sucesión de Pelayo hay algunos casos en los que pueden detectarse ciertos rasgos de matrilinealismo que justifican la llegada al trono de Alfonso I, de Silo y de Nepociano. 
Ermesinda, la hermana del rey Favila, podía ser la transmisora de los derechos de Pelayo, a su marido Alfonso I, hijo del duque Pedro de Cantabria. Cuando Favila muere tenía hijos varones que podían haberle sucedido, aunque no sabemos si tenía la edad suficiente para haber ocupado el trono. Situación semejante es la de la sucesión de Silo cuya única vinculación con el poder era su boda con Adosinda, hija de los anteriores. El tercer caso es el de la hija de Fruela II, mujer de Nepociano, que sucedió en Asturias a Alfonso II sin tener otra vinculación con el trono que esta boda. Este caso es el último en el que pueden detectarse estos rasgos de matrilinealismo. Aunque en estas sucesiones en las que median mujeres también puede descartarse la fuerza de la norma feudal que establece que las mujeres transmiten los derechos a sus hijos siempre que contraigan una matrimonio de acuerdo con su padre, para que el marido administre el feudo, en este caso sería el reino, hasta que se traspase al hijo. Este tipo de sucesión pone de manifiesto, la instrumentalización de las mujeres como vía de acceder a la posesión de un reino, como unos cuantos siglos después recogería Alfonso X en las Partidas. El tiempo ha pasado, pero el trato que reciben las mujeres no se ha modificado.

En los albores del siglo XI hay más ejemplos de la utilización de las mujeres de la realeza. Se esgrimía su papel de transmisoras para apoderarse de un substancioso bien, posiblemente sin pedirles opinión. Estas mujeres fueron Mayor/Munia de Castilla, Sancha de León , Urraca de Castilla, Teresa de Portugal, Petronila de Aragón, Leonor de Navarra y, por fin, Isabel la Católica y su hija Juana. La norma feudal se cumple estrictamente en todas estas sucesiones. El matrimonio con Mayor dio pie para que su marido Sancho III de Navarra pudiera reclamar el derecho a la herencia castellana, vacante tras el asesinato en las gradas de San Isidoro del infante García hermano de Mayor. Esta herencia a la muerte del rey la recibió su segundogénito Fernando, que pasó a titularse rey de Castilla. Lo mismo sucedía con Sancha de León, cuando su hermano Vermudo III fue derrotado y muerto en Támara (1038). Su propio vencedor Fernando I, que estaba casado con una hermana del finado, incorporó el reino de León a la Corona de Castilla. Estas dos mujeres habían actuado como meras transmisoras de sus reinos a sus hijos a través de sus maridos. No hay constancia de que al ser ellas las titulares de estos reinos intentaran incumplir la norma y participar en el gobierno. Por el contrario, su participación en la administración del reino fue escasa, puesto que ambas tenían marido. La 
norma feudal se cumplía escrupulosamente. Las mujeres transmitían el poder pero no participaban jurídicamente en él.

Muy distinta es la actitud de otras mujeres de la familia real castellana. Las anteriores cumplieron perfectamente con lo que el modelo femenino establecía. Pero no todas fueron así, puesto que también hubo mujeres que no estuvieron de acuerdo y adoptaron actitudes que no eran las propias de su género. Fueron las tres Urracas y Teresa. Otro tanto hizo Toda de Navarra sobre la que ya escribí en otra ocasión. Urraca, hermana de Sancho III, casó en 1022/24 con Alfonso V de León del que pronto enviudó. Ella aprovechó la juventud de su hijastro Vermudo III al que relegó a un segundo término siendo ella la que gobernó en León. Ella no tenía derecho al poder pues era reina consorte, pero por su propia iniciativa lo ejerció y gobernó con decisión, gracias a contar con apoyos importantes para poder llevar esto a cabo, no puede olvidarse ni a su importante hermano Sancho III, sin duda el mayor poder en la Península en aquel momento, que posiblemente a través de ella pretendía extender su influencia en León. En este caso la realidad social se impone a la norma.

Otro tanto pasó con la infanta Urraca de Castilla, hija de Fernando I, la cual durante el reinado de sus hermanos Sancho II y, sobre todo, Alfonso VI, tuvo una destacada actuación. Urraca logró un poder efectivo que la permitió decidir e intervenir en hechos importantes del momento. Ambas Urracas, a las que unía el parentesco, una era tía abuela de la otra, no se contentaron con lo que la sociedad les deparaba y actuaron de forma inapropiada con lo se prescribía para una mujer pues invadieron espacios públicos, el poder político. Bien es cierto que esto lo pudieron hacer por su pertenencia al grupo más elevado de la sociedad, la nobleza real. Su origen fue el que les permitió sus actuaciones, pero no debe olvidarse que muchas otras mujeres en sus mismas circunstancias o con mayor derecho, como antes se veía con Mayor o Sancha, tuvieron que aceptar la subordinación a la norma.

Urraca de Castilla y su hermana Teresa de Portugal fueron, sobrinas ambas de las dos Urracas anteriores en distinto grado, fueron otro ejemplo de la existencia de mujeres que pugnaron en diversos ámbitos por no someterse a lo establecido para ellas. Alfonso VI murió sin heredero varón, con lo cual ambas transmitieron los derechos sucesorios a sus hijos, Alfonsos ambos como su abuelo. Urraca heredaba Castilla y Teresa Portugal. Este era un feudo de Castilla que tenía la consideración de condado y que Teresa había recibido cuando contrajo matrimonio con Enrique de Borgoña. Teresa 
no aceptó la dependencia vasallática de Castilla y comenzó a titularse reina cuando murió el padre de ambas en 1109, igual que Urraca lo hacía con respecto a Castilla. Las relaciones de ambas hermanas nunca fueron buenas. Teresa aprovechó los problemas que acontecieron en Castilla para consolidar una situación que después hubo que aceptarse en Castilla, logrando de esta manera Teresa la creación de un nuevo reino en la Península. Teresa, al igual que su hermana, no se consideraba mera transmisora de los derechos sucesorios a su hijo, como estaba establecido. Ella gobernaba con pleno derecho, no como regente de su hijo menor. Por ello cuando éste intentó hacerse con el poder ella se resistió y pretendió que Alfonso aguardara hasta su muerte para recibir la herencia, como hubiera hecho de ser un hombre quien ocupara el trono. Pero Alfonso no estaba de acuerdo con los deseos de Teresa y reclamó a su madre la herencia. Se llegó al enfrentamiento armado y las tropas de Teresa fueron derrotadas en Guimaraes (1128). Alfonso I se tituló entonces rey de Portugal. Ella tuvo que someterse ante la derrota pero no cedió sus derechos y siguió titulándose reina hasta su muerte (1130). Alfonso arrebató el poder a su madre en cuanto pudo, como era lo habitual, pero Teresa, había mantenido la iniciativa política mientras pudo ejerciendo la "potestas", que le correspondía por ser heredera, no mera transmisora de la misma, esto, en cambio, no era lo habitual.

Otro tanto sucedió con Urraca, aunque aquí la situación se complicó más. Urraca, al igual que Teresa, había recibido Galicia en feudo al contraer matrimonio con Raimundo de Borgoña, cuando éste murió ella continuo en Galicia gobernando en nombre de su hijo Alfonso Raimúndez. A la muerte de Alfonso VI, su nieto todavía era niño y no podía hacerse cargo del gobierno del reino. Ésta fue una posibilidad que se tuvo en cuenta, pero se acabó desechando y se designó como heredera a Urraca, por ser hija legítima, frente a Teresa. Pero la herencia castellana era complicada pues había parientes varones prontos a reclamarla y con poder suficiente para así hacerlo. Alfonso I de Aragón, biznieto como Urraca de Sancho III el Mayor, era el principal candidato. El peligro era inminente, por ello en Castilla, se optó por pactar un matrimonio entre Urraca y Alfonso para evitar el más mínimo conflicto. Además, se cumplía con la norma feudal de buscar a la heredera un marido que se encargara de la administración del feudo.

Pero los conflictos no se evitaron sino todo lo contrario. Alfonso de Aragón era defensor a ultranza de la norma patriarcal y feudal y pretendía ejercer en Castilla la "potestas", cosa que Urraca no estaba dispuesta a tolerar. Ella era hija de rey y consideraba que tenía derecho a la herencia de 
su padre, no solo a la transmisión de la misma. El conflicto entre Urraca y Alfonso fue éste y se complicó con otros muchos. Se ha argumentado la falta de entendimiento de un matrimonio impuesto a Urraca, los intereses de Teresa de Portugal en desestabilizar Castilla, los conflictos sociales en la propia Castilla, los intereses de la nobleza castellana, etc. La lucha armada llegó a extenderse por el territorio, pero Urraca no cedió en sus derechos que defendió con las armas y que logró imponer. Ella fue reina de Castilla hasta su muerte, cuando su hijo contaba ya veintiún años, edad suficiente para haber recibido con anterioridad la transmisión de derechos por parte de su madre. Urraca no se subordinó al modelo establecido y no solo transmitió, sino que ejerció el poder.

La actuación de estas dos mujeres es una excepción a la norma que se mantuvo firme durante todo el Medievo. Ellas aprovecharon unas coyunturas especiales y unos intereses de grupos de poder para lograr hacer valer unos derechos legítimos y participar en el poder. Pero nada cambió en el marco jurídico. La subordinación de las mujeres siguió manteniéndose como se comprueba en el caso anteriormente estudiado de Berenguela de Castilla, posterior en un siglo. Otro tanto puede decirse sobre Petronila de Aragón, que ya analicé en otro lugar, por lo que solo me referiré a ella brevemente.

Petronila tuvo la misión de ser la transmisora de la sucesión en el reino de Aragón entre su padre Ramiro II y su hijo Alfonso II. Ella heredo el "regnum" y la "potestas" y . La norma feudopatriarcal impedía que las mujeres ejercieran la "potestas", por ello era necesario casar a Petronila con alguien que pudiera ejercerla y que sirviera de puente entre Ramiro y su nieto. La situación es idéntica a la de Urraca de Castilla. Pero en este caso todo funcionó de acuerdo con lo establecido. Ramón Berenguer IV , conde de Barcelona, fue el elegido para casarse con Petronila y gobernar el reino hasta que su futuro hijo pudiera hacerse cargo de la herencia de Ramiro II, como así sucedió. Petronila se mantuvo dentro de la norma y se subordinó a lo establecido, cumplió a la perfección con el modelo femenino y se mantuvo, a pesar de ser reina, dentro de lo doméstico sin participar en el poder, fueron los hombres de su familia quienes dispusieron todo, su padre, su marido y su hijo.

No pienso que esta diferencia entre Petronila y Urraca y Teresa se deba a que en Aragón la norma feudal tenga mayor fuerza que en Castilla o en Portugal, como tantas veces se ha defendido. Creo que las diferencia entre ellas se debe, sobre todo, a la coyuntura de cada momento, puesto que 
el patriarcado es el mismo en la parte oriental que en la occidental de la Península. Urraca y Teresa se beneficiaron de unas circunstancias especiales que les propiciaron eludir una subordinación que era la norma general para todas las mujeres. Petronila no encontró la coyuntura política apropiada o no fue consciente de sus derechos, por ello se mantuvo dentro de lo que era lo habitual. Además, la situación de Berenguela fue idéntica a la de Petronila, con lo cual el argumento de la mayor o menor fuerza del feudalismo en un lugar $u$ otro del territorio peninsular no se sustenta tampoco en lo referente a las mujeres. Bien es cierto que para ellas, aunque el sistema feudal influye en las relaciones sociales, lo fundamental es el sistema patriarcal que marca todos los acontecimientos de la vida de todas las mujeres.

Volviendo a Castilla es necesario señalar que aquí se produce por escrito por primera vez una referencia explícita de los derechos de las mujeres a heredar la Corona. Alfonso $\mathrm{X}$ designó como heredera a su hija Berenguela (1255) al no tener todavía hijos varones. La designación se mantuvo hasta el nacimiento de Fernando de la Cerda, que por su condición masculina se prefirió a Berenguela. En la obra jurídica del monarca se hace referencia a esta posibilidad. En la II Partida y en El Espéculo se trata de este tema y sobre la reina y las mujeres de la familia real en general. En El Espéculo las normas se refieren sobre todo a la guarda y honra de la persona de la reina. Aunque el respeto hacia la reina debe ser el mismo que el que recibe el rey, sobre ella lo que más preocupa es la guarde de su honra. El adulterio de la reina es condenado con la muerte. Las razones por las que se impone esta pena son la deshonra del rey y el que la reina debe ser ejemplo para todas las mujeres. Pero la misma pena que recibe el adulterio de la reina se da al adulterio que pueda cometer cualquier otra mujer que el rey tuviese aunque no fuera "a bendición". Lo cual demuestra que la transmisión de la herencia dentro del linaje es la primera preocupación que domina toda la sociedad.

La proximidad de la reina y de las infantas al poder real es el motivo que lleva a Alfonso $\mathrm{X}$ a elaborar una minuciosa legislación sobre ellas en la que se diseña perfectamente su función, su papel dentro de la realeza. El Espéculo establece como debe guardarse la persona de la reina y se legisla sobre los delitos que contra ella se pudieran hacer. Su cercanía al rey, marido o hijo, hace que las penas que se impongan sean semejantes a las que se imponen a los que atentan contra el rey. En el título XV del libro II, se establece como debe ser la casa de la reina y que trato deben recibir las mujeres que la forman, así como cual debe ser su funcionamiento. Los 
bienes de la reina reciben trato semejante a los del rey. No obstante, de toda esta legislación no se desprende un trato semejante o de igualdad para ambos reyes, por el contrario hay un gran proteccionismo con respecto a la reina. Se la considera como un menor al que hay que tutelar cuidadosamente $y$, sobre todo, velar para que no caiga en adulterio. El hombre causa de ello sería castigado con la muerte. Era el único caso que un hombre recibía esta pena por la intervención en un suceso que para él no tenía la consideración de delito, pues cuando el adulterio era con cualquier otra mujer la única penada era ella. La reina aparece en la legislación alfonsí como una propiedad del monarca por lo que debe ser tratada como todas las otras propiedades, recibiendo el mismo trato, honra y respeto que todo lo que se relaciona con la Corona, puesto que cualquier ofensa que ella pudiera recibir, en ultimo extremo era ofensa que se hacía al rey. Pero esta situación es semejante a la de cualquier mujer, la honra del marido es la que hay que mantener.

En las Partidas la legislación es más extensa. El título Como el pueblo debe guardar al rey en su mujer la reina de la ley I de la II Partida establece claramente que la honra de la reina no proviene de ella sino de ser la mujer del rey. Esta Partida es la que se dedica al tema de la reina y en ella se elabora toda esta legislación que se repite en El Espéculo, pero se añaden otros aspectos importantes. Por ejemplo, cuando se tratan de los caminos por los que se puede conseguir un reino se reconoce como tercer vía "el casamiento con dueña que es heredera de "regnum", matrimonio que pueden contraer incluso individuos nobles pero no pertenecientes al linaje real, a esto aludía anteriormente. El título VI de la Partida trata íntegramente de las relaciones entre el rey la reina. Se establecen primero cuales deben ser las condiciones que el rey debe buscar en la futura reina, a la cual debe amar y honrar hasta el extremo de no tener más de una mujer. Debe ser guardada para evitar que cometa adulterio, por la preservación de la honra real. Ella debe ser responsable de la primera educación de sus hijos e hijas. Éstas permanecerán con ella hasta que contraigan matrimonio, la reina es la encargada de velar por ellas y completar su educación, sobre la que se legisla minuciosamente, separando cuidadosamente la educación de los hijos de la de las hijas.

En las Partidas, Alfonso $\mathrm{X}$ establece una nueva norma para la sucesión en la Corona, influida por el Derecho romano y diferente a la norma feudal, que causo una serie de conflictos en Castilla, pues suponía la introducción del Derechos romano, pero éste no es el tema que aquí me 
ocupa. En cambio, si es necesario enfatizar que por primera vez aparece recogido en un escrito jurídico el orden de las mujeres en la sucesión al trono y sus derechos al mismo. Bien es cierto que los parientes varones son preferidos siempre a las mujeres, pero en caso de faltar éstos las mujeres tienen derecho a heredar el trono. Es importante señalar que aquí ya no aparecen como meras transmisoras, sino que se acepta que ante la carencia de un pariente masculino una mujer pueda llegar a ostentar el poder plenamente, no solo la "potestas", sino también la "autoritas". Bien es cierto que sus derechos no son iguales a los de los hombres pues se anteponen a las mujeres sus hermanos menores e, incluso, los sobrinos menores, hijos de sus hermanos.

La legislación alfonsí responde a la mentalidad del momento. Las mujeres aparecen como seres débiles a los que hay que proteger según preconizaba el ideal caballeresco, al mismo tiempo como ser inferior y proclive al pecado como enunciaba la escolástica, pero a la que hay que reconocer sus derechos a la herencia paterna como establece el Derecho romano.

La llegada al trono de Isabel la Católica y de su hija Juana se fundamentan en esta base jurídica. No haré más que una referencia a estos hechos por haber tratado largamente ya sobre ellos en otros escritos. No obstante, la práctica feudal en la sucesión todavía no ha desaparecido. Isabel pudo defender sus derechos al trono de su hermano pues éste no tuvo ningún hijo varón y es otra mujer la que se le oponía. Ésta es Juana la hija de Enrique que también aducía sus legítimos derechos establecidos por la ley de Partidas, como se acaba de señalar. Isabel debía buscar ayuda exterior pues la situación era complicada y tenía un peligroso contrincante en Fernando de Aragón pariente superstite más próximo a Enrique IV, si exceptuamos el propio padre de Fernando Juan II de Aragón. La boda de Isabel con Fernando era una manifestación de inteligencia política que llevo a Isabel al trono castellano. Con este enlace Isabel lograba un poderoso aliado, la Corona de Aragón, pero al mismo tiempo controlaba a un candidato que podía hacer peligrar su apetencia del trono. Lo cual quiere decir que el reconocimiento de los derechos de las mujeres a la herencia en el poder no eran tan aceptados como prescribía la norma jurídica. Como es conocido, y ya analice en otro lugar, cuando Enrique IV murió, Isabel no esperó el regreso de Fernando, que estaba en Aragón, para coronarse reina de Castilla. Fernando se enojó fuertemente por ello, pero tuvo que aceptar los hechos consumados y, por ello se llegó a la Concordia de Segovia. Uno 
de los argumentos, según Pulgar, que Isabel esgrimía era que en aquel momento no tenían más que una hija, Isabel "me podría acaecer que, después de nuestros días, viniese alguno que por ser varón ... alegase pertenecerle estos reinos, e no a vuestra hija la princesa".

Isabel la Católica logró el poder pleno como reina de Castilla. No es el momento aquí de valorar su legitimidad respecto a él con referencia a su sobrina Juana, pero si señalar que fueron dos mujeres las que pugnaban en Castilla por la herencia de la Corona. Otra mujer fue la heredera de Isabel, su hija Juana. Posiblemente la actuación decidida de Isabel con respecto al poder, del que no estaba dispuesta a ceder nada, hizo que el tratamiento que recibiera Juana fuera diferente. A ella no se le discutió la herencia en Castilla, es decir, la sucesión en el "regnum", pero tanto su marido Felipe, como su padre Fernando o su hijo Carlos, todos ellos arbitraron los medios oportunos para que recibiera un tratamiento de incapaz y tuviera que ceder el gobierno en manos masculinas. Juana siempre ostento la Corona, aparece como reina en la documentación hasta su muerte. Pero nunca logro la "potestas" que sucesivamente y alegando unos motivos u otros tuvieron los hombres de su familia. La norma escrita por Alfonso X reconocía unos derechos para las mujeres que todavía dos siglos después era difícil disfrutar, había que luchar, como hicieron Urraca, Teresa o Isabel, para lograr aquello a lo que había derecho.

\section{BIBLIOGRAFIA}

Abilio BARBero De AgUILeRA, Pervivencias matrilineales en la Europa medieval: El ejemplo del norte de España, "La condición de la mujer en la Edad Media", Madrid, 1986, 215-222.

Cristina Segura Graíno, Las mujeres y el poder en la España visigoda, "Homenaje al Profesor Juan Torres Fontes", II, Murcia, 1987, pp. 1.593-1. 601.

-, Las mujeres y la sucesión a la Corona en Castilla en la Baja Edad Media, "En la España Medieval”, 12(1989), pp. 205-214.

-, Derechos sucesorios al trono de las mujeres en la Corona de Aragón, "Homenaje al Profesor Santamaría. Mayurca", 22 (1989), pp. 591-599.

-, La sucesión femenina a la Corona en el Reino de Navarra, "Homenaje al Profesor Luis Díez de Salazar", San Sebastián, 1992, pp. 203-210. 


\section{RÉSUMÉ}

Le système de genre reclure aux femmes dans les espaces domestiques, tant que assigne aux hommes les espaces publiques dans lesquels la politique se débrouille, c'est pour cela que les femmes sont exclues du pouvoir politique. Cependant, comme la société féodale défend la transmission du patrimoine dans la lignée, elle permet que, dans quelques cas, les femmes peuvent servir comme intermédiaires dans la transmission du pouvoir entre les hommes de leurs familles. Par cette raison, quelques femmes sont arrivées à hériter le pouvoir politique. Dans quelques cas, les femmes ont gouverné comme régents de leurs garçons ou leurs frères.

On analyse les cas que dans les royaumes péninsulaires se présentent comme reines ou régents, concluant que l'exclusion des femmes de la politique peut s'abandoner pour que le royaume reste dans la famille. Selon les circonstances, on prend les décisions sur la relation des femmes avec le pouvoir politique, s'occupent aux intérêts de chaque moment.

\section{SUMMARY}

Women are placed in the domestic spaces by the system of genus, whereas men are assigned to the public spaces, where the politics is unrolled, because of that women are excluded from the political power. However, as the feudal society defends the transmission of the inheritance, it permit women may serve like intermediary in the transmission of the power between men of their family. Because of that, some women have arrived to inherit the political power. In other cases, women have governed like regents of their sons or their brothers.

The cases which present queens or regents in the peninsular kingdoms are analysed, concluding that the exclusion of women of the political may be abandoned, so as the kingdom remain into the family. Depending on the circumstances, the decisions about women's relationship with political power are taken attending to interests of every moment. 